\title{
ACESSIBILIDADE ENTRE MUNDOS: uma arquitetura mais inclusiva aos autistas
}

\author{
VERGARA, Lizandra Garcia Lupi (1) \\ TRONCOSO, Marcia Urbano (2) \\ RODRIGUES, Gabriela Vargas (3) \\ (1) Universidade Federal de Santa Catarina, Doutora. \\ e-mail:I.vergara@ufsc.br \\ (2) Universidade Federal de Santa Catarina, Doutoranda. \\ e-mail:marciaurbanotroncoso@gmail.com \\ (3) Universidade Federal de Santa Catarina, Mestranda. \\ e-mail: vargasrodriguesgabriela@gmail.com
}

\begin{abstract}
RESUMO
Diariamente as crianças com autismo têm que enfrentar diversas dificuldades e barreiras que a sociedade produz, tais como: limites arquitetônicos nos ambientes construídos, barreiras ergonômicas, atitudinais, sociais, metodológicas e pedagógicas. A existência destas dificulta ou até mesmo impede a garantia de igualdade social. Este artigo pretende identificar algumas diretrizes importantes para a proposição de soluções projetuais a ambientes escolares propostos, por meio da adequação dos espaços organizados e compartimentados em função das atividades desenvolvidas por crianças autistas e expandir o diálogo entre os profissionais que podem contribuir para que seja realizada a inclusão efetiva destas crianças.
\end{abstract}

Palavras chave: autismo; inclusão; ergonomia e ambiente construído.

\begin{abstract}
Daily children with autism need to face some difficulties and barriers that society produces, such as: architectural barriers in built environments, social and ergonomic limits, educational and methodologic constraints. These difficulties don't help, and sometimes deny the real social equality. This article intends to identify some important guidelines to propose project solutions to educational environments, through the adequacy of organized spaces according to the activities of the autistic children, and so, expand the dialog among professionals that can contribute to the real inclusion of these children in the world.
\end{abstract}

Keywords: autism; inclusion; ergonomics and built environments.

\section{INTRODUÇÃO}

O presente artigo trata de chamar a atenção para as necessidades de crianças autistas, no que se refere à sua relação com o ambiente construído, principalmente na arquitetura escolar. Entendendo que as necessidades dos portadores de Transtorno do Espectro Autista (TEA) envolvem, sobretudo, questões de caráter sensorial, admite-se que as soluções 


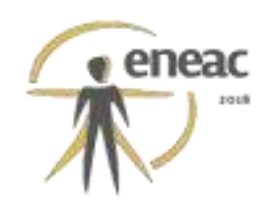

destas dizem respeito ao campo da ergonomia que também se preocupa com a criação de ambientes acessíveis a todos.

Nessa pesquisa, os estudos ergonômicos baseiam-se na aplicação conjunta de vários conhecimentos para alcançar dados sobre o homem e suas relações com o ambiente construído, visando encontrar a melhor solução para adaptá-lo. Neste sentido, são utilizados os estudos de acessibilidade espacial que se apropriam dos conceitos da ergonomia, que é o estudo do comportamento humano frente às interfaces. Os elementos do ambiente considerados pela ergonomia são aqueles referentes à percepção ambiental, o conforto, aos materiais de acabamento e revestimentos e aos postos de trabalho - mobiliário e layout considerando, também, os dados antropométricos (RIBEIRO, MONT'ALVÃO, 2004).

As percepções e sensações do ser humano estão diretamente pautadas ao ambiente que o envolve, afetando seu comportamento. O intercâmbio comportamental do homem com o ambiente construído contextualiza as necessidades e a compreensão do uso dos espaços.

O meio ambiente construído como linguagem tem o poder de definir e aperfeiçoar a sensibilidade. Pode aguçar e ampliar a consciência. Sem arquitetura, os sentimentos sobre o espaço permanecem difusos e fugazes... A forma construída tem o poder de aumentar a consciência do sentido de interior e exterior, intimidade e exposição, vida privada e espaço público. (TUAN, 1983, p. 119)

Autistas apresentam características que diferenciam sua percepção, limitando, muitas vezes, o seu conhecimento do mundo. Não compreendem facilmente a partir do todo, costumam focar mais as partes e os detalhes. Apresentando distúrbios que provocam uma confusão na percepção das informações e na interpretação dos sentidos, o mundo passa a ser uma fonte de ruídos, odores e poluições visuais, ou seja, um cenário caótico, que pode causar insegurança e instabilidade.

O ambiente "fala", transmite-nos sensações, evoca recordações, passa-nos segurança ou inquietação, mas nunca nos deixa indiferentes. O espaço [...] possibilita oportunidades para a aprendizagem, por meio das interações possíveis entre crianças e objetos e delas entre si. A partir desta perspectiva, o espaço nunca é neutro, podendo ser estimulante ou limitador de aprendizagens, dependendo das estruturas espaciais que estão postas e das linguagens que estão representadas. (REDIN, MÜLLER, REDIN, 2007, p. 102)

Segundo a American Association on Mental Retardation (AAMR, 2002) existem pelo menos três níveis diferentes de ambientes importantes que promovem as interações de um indivíduo: o social imediato, incluindo o indivíduo e a seus familiares; o social próximo, os vizinhos, comunidade e a escola; e o sociocultural que envolve a população em geral, a cultura, as leis e as normas.

Estes três níveis de relações dos indivíduos com o ambiente serão abordados neste artigo na tentativa de promover melhor compreensão do mundo da criança autista, pois se percebe que houve um grande aumento na demanda de espaços escolares inclusivos por eles. De acordo com o site da Rede de Monitoramento de Autismo e Deficiência do Desenvolvimento dos Centros de Controle e Prevenção de Doenças (Center of Disease Control - CDC), o diagnóstico de TEA aumentou cerca de 30\% no período de 2012/2014, passando de 1 a cada 88 crianças para 1 a cada 45. (CHAVES DIAS et al, 2018).

Se continuar neste ritmo, em 2050, chegaremos à relação de um para um, quadro que demonstra uma urgência da oferta de espaços inclusivos, internos e externos, para indivíduos que passam a maioria do tempo isolados no interior de suas casas, inseguros, com pouca autonomia, e dependendo de cuidadores para sobreviver. 


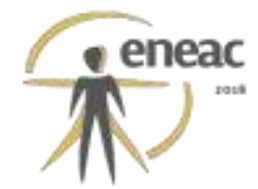

Ambientes construídos por arquitetos já consideram a presença de cadeirantes ao projetar suaves rampas que permitem a todos o pleno direito de ir e vir. Mas infelizmente ainda há pouco conhecimento sobre as dificuldades sensitivas dos autistas, que pretendem ser divulgadas neste artigo para contribuir à construção de espaços escolares que realmente estejam adequados a todos. Pequenas intervenções podem ser feitas, para que a arquitetura funcione como uma capa protetora entre o mundo interno do autista e o mundo externo à sua volta. E o ambiente escolar pode promover esta acessibilidade entre mundos.

\section{O SOCIAL IMEDIATO: A CASA DO AUTISTA}

O social imediato promove interações da criança autista com seus familiares e é onde surgem os primeiros laços de convívio com o outro, onde, segundo Grandin:

Pais e cuidadores precisam colocar as crianças no mundo, porque elas não vão se interessar por coisas com as quais não tem contato... Seus pais os deixaram cair numa rotina que nunca varia e não traz experiências novas... Até os autistas com problemas graves precisam ver o mundo... serve estar perto de casa. Não em casa, mas perto de casa. É essencial que a criança saia de casa... (GRANDIN, 2016, p. 194)

A palavra autismo, formada por auto (do gr. - referente a si mesmo) + ismo (sufixo que indica ação ou estado), reforça a escassa interação dos indivíduos portadores do distúrbio com seus semelhantes, pois eles estão focados em si e não nos outros, já que possuem grande dificuldade para perceber quem fica "lá", no lugar mais distante, se identificando mais com o 'aqui', e assim preferindo a segurança de ambientes mais conhecidos como o interior de suas casas.

O meio-ambiente constitui-se sendo o elemento essencial para a estruturação mental da relação espaço-tempo, já que a cognição da realidade dá-se a partir de noções espaço-temporais, "o tempo está implícito em todos os lugares, nas ideias de movimento, esforço, liberdade, objetivo e acessibilidade". As distâncias, o espaço, os percursos, o "perto" e o "longe" passam a ser compreendidos pelo esforço e não podem ser medidos a partir de referenciais de pessoas que não apresentam nenhuma dificuldade em seus deslocamentos. (TUAN, 1983, p. 96)

Para qualquer bebê, típico ou atípico, a casa é o ambiente social mais imediato e seu quarto representa o lugar mais seguro. Naturalmente, quando soltos na amplidão do vazio, fora da proteção de suas casas, estes experimentem uma mistura de medo e liberdade. Assim, a criança começa a distinguir o lugar como "pausa" e o espaço como "movimento". Experimentam desde cedo os opostos, entre o interior/exterior, pausa/movimento, conceitos de extrema importância para uma coerente estruturação corporal de uma criança que constrói seu conhecimento a partir da vivência do seu Eu situado no mundo.

Nossos corpos e movimentos estão em constante interação com o ambiente; o mundo e a individualidade humana se redefinem um ao outro constantemente. A percepção do corpo e a imagem do mundo se tornam uma experiência existencial contínua; não há corpo separado de seu domicílio no espaço, não há espaço desvinculado da imagem inconsciente de nossa identidade pessoal perceptiva. (PALLASMA, 2011, p. 38) 


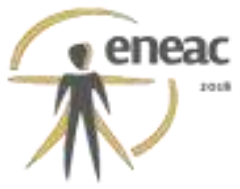

Figura 1: Crianças interagindo com o ambiente

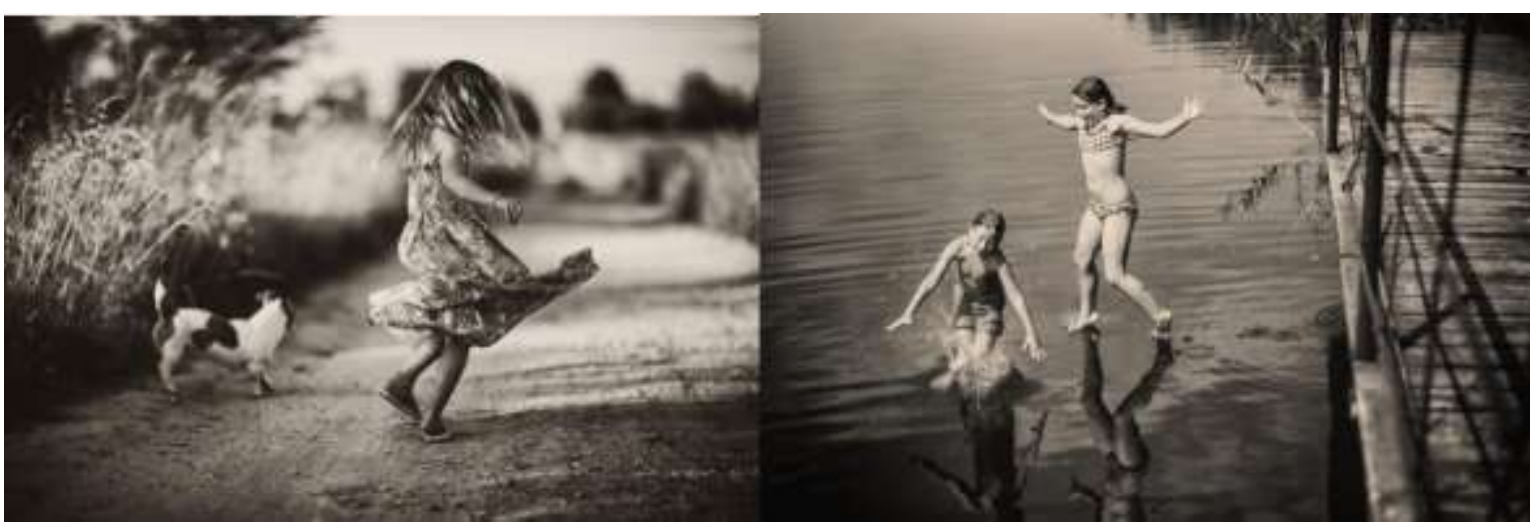

Fonte: Savaris, 2015.

A comunicação do ser humano com seu entorno é feita por meio dos cinco sentidos: visão, audição, olfato, paladar e tato. $E$ foi a evolução dessas formas de perceber o meio ambiente que ajudou a nossa espécie a sobreviver no planeta. Mas o que acontece quando estas percepções funcionam de forma diferente do que é considerado normal?

Em seu livro O cérebro autista: pensando através do espectro, Temple Grandin (2014) afirma que nove entre dez pessoas com autismo apresentam um ou mais transtornos sensoriais que interferem na sua capacidade de gostar e sentir prazer em um mundo difícil de ser codificado.

Suspeito que os pesquisadores simplesmente não entendem a urgência do problema. Eles não conseguem imaginar um mundo onde roupas que pinicam o fazem sentir-se pegando fogo, ou onde uma sirene soa como se alguém estivesse perfurando meu crânio com uma furadeira... como socializar pessoas que não toleram o ambiente onde devem se mostrar sociáveis? (GRANDIN, 2016, p. 80).

O autismo não é uma doença, mas um distúrbio neuronal. Na maioria dos casos sua origem é genética, no entanto influências ambientais e comportamentais também atuam como estímulos para o início de seu desenvolvimento. Muitos médicos não acreditam em uma cura total, mas existem bons resultados em tratamentos feitos até os sete anos, época em que o cérebro ainda está em fase de crescimento. Moldar este importante órgão, ao ativar sinapses em outras áreas não danificadas, amenizaria confusões perceptivas em pequenos autistas.

Se durante a infância já foi comprovado que terapias comportamentais parecem influenciar positivamente no tratamento de crianças autistas, acreditamos que um ambiente especial também pode favorecer estas crianças em seu processo de compreensão do mundo. Portanto além de detectar o diagnóstico o mais cedo possível e investir em diversas terapias, na fase infantil, como um bom caminho para ajudá-los, a arquitetura, principalmente de espaços terapêuticos, creches e escolas, poderia servir como uma casca protetora, ao amenizar o excesso de informações que estes pequenos autistas recebem do mundo externo.

Crianças com TEA geralmente possuem neurônios extras em seu cérebro, que as deixam elétricas e antenados o tempo todo, assim, parecem nunca desligar. Os cinco sentidos ficam ativos, captando tudo, e às vezes elas não conseguem identificar o que é prioridade para o momento. Tratamentos acústicos nos ambientes das salas escolares que isolem o excesso de ruído externo, pérgolas que diminuam fortes incidências solares, seriam pequenos exemplos onde a arquitetura escolar poderia cooperar com a inclusão destas crianças que merecem esses cuidados para se sentirem mais acolhidas no meio ambiente social. 


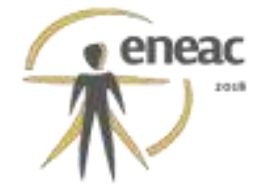

Geralmente a maioria dos autistas são muito sensíveis à luz solar e possuem uma visão fotográfica detalhista que os distraem do foco principal. Eles sentem todos os aromas do ambiente, desde o perfume da professora ao lanche do colega, o que, às vezes, os fazem enjoar. Devido ao seu delicado paladar, alguns não suportam misturar texturas, cores e sabores distintos de comida. E, com o tato à flor da pele, podem confundir um abraço apertado de um toque agressivo. Alguns escutam qualquer barulho com a mesma intensidade, dentro e fora do ambiente, tal como o comando de voz na sala de aula ou o som do grilo no jardim.

Figura 2: A percepção dos sentidos
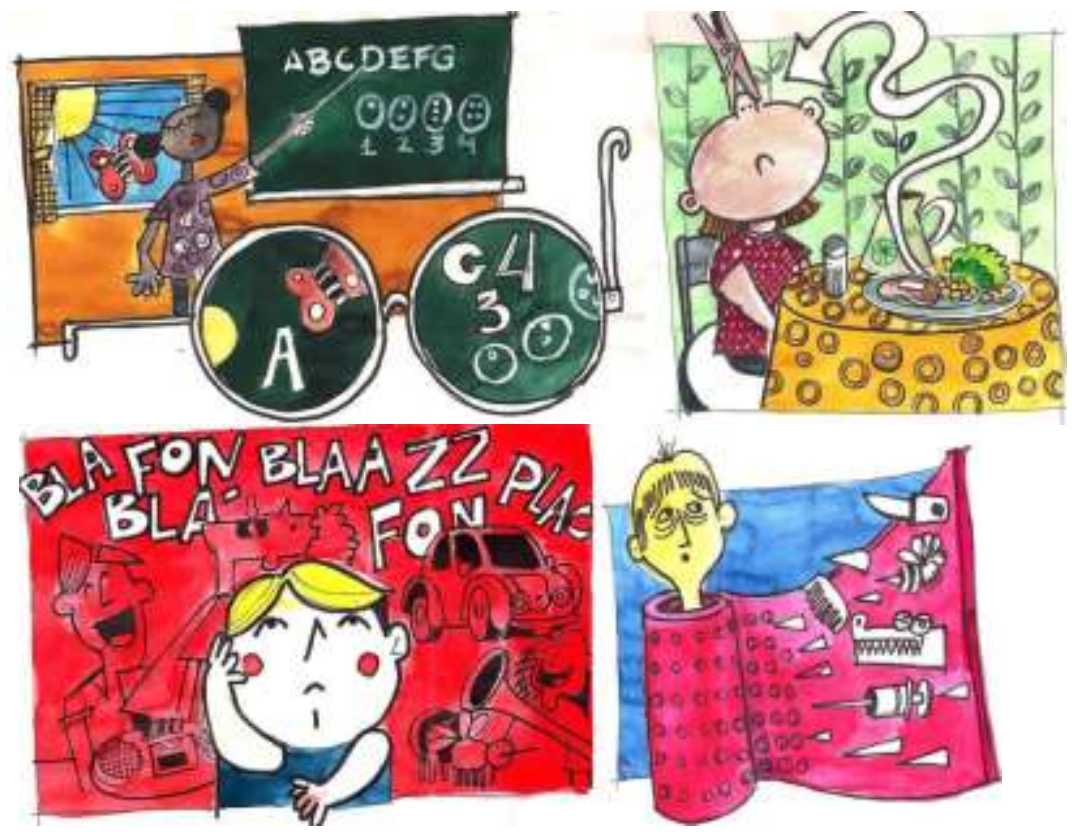

Fonte: Desenhos de Eliel Américo Santana da Silva, 2017.

Atentas a todas as informações ao mesmo tempo, as crianças com TEA absorvem tudo, ou seja, é casual que por vezes precisam se isolar para recarregar suas baterias. Para tanto ambientes escolares poderiam providenciar pequenos espaços de escape, como alguns nichos ou cantos onde os autistas pudessem ir para eventualmente se isolar de tudo para assim descansar alguns minutos do intenso convívio social.

Figura 3: Exemplos de espaço de fuga
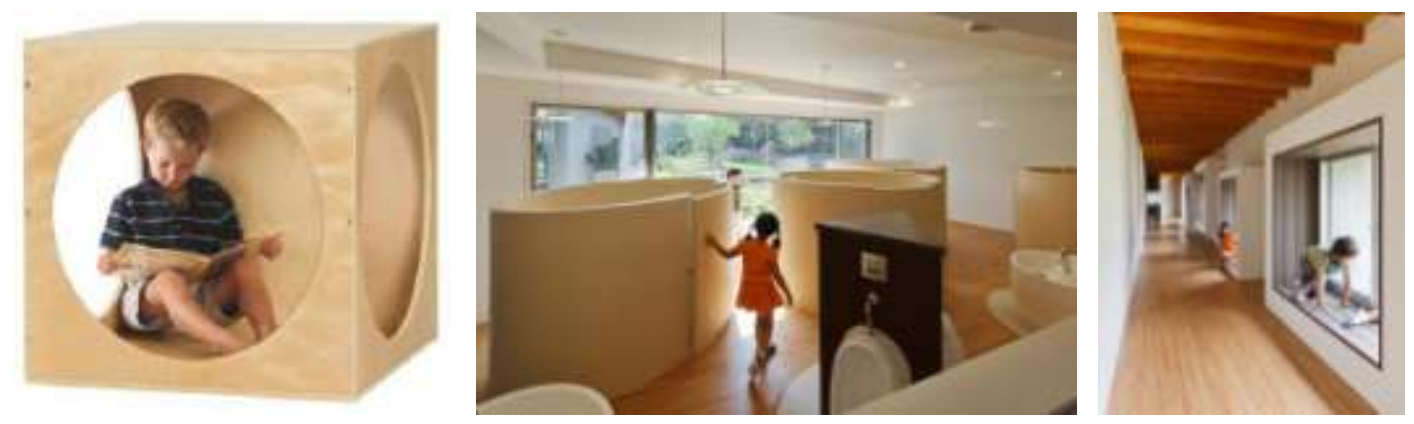

Fonte: Archdaily, 2015.

Quando autistas evitam olhar nos olhos é como uma defesa para conseguir entender o que o outro diz sem se distrair com o movimento do rosto à sua frente. Para eles o mundo real já 


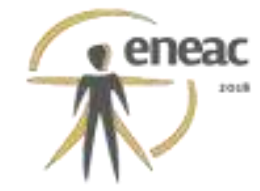

oferece muita informação, ficando mais complicado ao tentar entender mensagens subliminares, como as que uma expressão facial pode transmitir. Crianças com TEA entendem mais o lado racional do que o emotivo, e por isso preferem as coisas mais concretas, evitando se complicar com a difícil interpretação de metáforas de duplo sentido.

Socializar mesmo não sendo algo natural para um portador de TEA, é um processo lento, onde ele aprende, de memória, a como se comportar. Por isso as mães de autistas devem insistir na ajuda da escola com suas auxiliares, quando necessário. Muitas crianças autistas desejam ter amigos, mas simplesmente não sabem como interagir. Elas precisam ser ensinadas a reagir a situações sociais e a ter um repertório de respostas para usar em vários momentos.

A maioria da população infantil entre 2 a 7 anos, já começa a frequentar creches e escolas ampliando assim suas esferas sociais. O cotidiano das crianças autistas também deveria perpassar por estes contextos diversificados, promovendo suas chances de ascensão e de bem-estar em espaços variados.

Mas por receio ou excesso de proteção, a maioria dos pais ou cuidadores de autistas, acabam limitando a vida destes apenas aos ambientes do social imediato, aquele que corresponde à relação da criança com seu próprio $\mathrm{Eu}$ e o ambiente doméstico familiar. $\mathrm{E}$ assim muitos autistas permanecem a maior parte do tempo de suas vidas dentro de suas casas, visitando apenas parentes mais próximos que aceitam e entendem, sem criticar, algumas de suas exóticas estereotipias.

Com vergonha, ou cansados de ter que explicar a todos que olham com estranheza os movimentos repetitivos de seus filhos, alguns pais acabam levando-os no máximo a algumas clínicas terapêuticas que os ajudam nos tratamentos, o que leva a que estas famílias praticamente não possuam momentos de lazer no seu dia a dia, evitando idas a parques, praças, shoppings, restaurantes e/ou cinemas. Muitos, inclusive, chegam ao limite de não mais matricular seus filhos autistas em uma escola regular, na tentativa de resguardá-los de possíveis bullyings feitos por colegas em sala de aula.

\section{O SOCIAL PRÓXIMO: UMA ESCOLA INCLUSIVA}

A escola é o primeiro espaço de vivência pública da criança e é onde se constrói a condição de cidadão de cada indivíduo (DISCHINGER et al, 2004, p. 11). No entanto na realidade de ensino regular no Brasil, não se vê uma efetiva inclusão, e a aplicação das leis que defendem este direito para os autistas é uma tarefa complicada, visto que é necessária uma grande escala de reformas educacionais que envolvem capacitação dos profissionais e intervenções na arquitetura e infraestrutura das escolas, dentre de outros fatores.

Déoux (2010) cita que uma arquitetura mal concebida pode potencializar episódios de incapacidade, e até de exclusão. Nas escolas geralmente não são consideradas as necessidades específicas de todos os alunos. A arquitetura poderia proporcionar uma maior independência, mas, o que se vê na atualidade é que a preocupação com a acessibilidade se limita somente às necessidades físicas.

Mas como poderíamos criar um ambiente que considere a criança, suas diversas manifestações afetivas, sociais, culturais, que potencialize a criação, a descoberta e a produção de sentidos? (REDIN, MÜLLER, REDIN, 2007).

Segundo Dischinger et al (2004) pode-se identificar a natureza dos problemas levantados nas escolas e classificá-los sob três aspectos distintos: relacionados à mobilidade, orientabilidade e usabilidade. Que, segundo os autores podem ser percebidos como: mobilidade - aspectos que dificultam o deslocamento de pessoas e que podem em risco a 


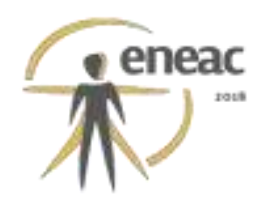

segurança e o conforto da criança; orientabilidade - dificuldade de identificar a escola e suas divisões internas e; usabilidade - dos equipamentos e materiais necessários para 0 atendimento a todos com equidade.

Os ambientes escolares deveriam adequar-se aos alunos e não o inverso. Hoje infelizmente na maioria dos casos o aluno com deficiência tem tentado se adaptar às arquiteturas das escolas brasileiras. Em um verdadeiro modelo de inclusão, a existência da diferença deveria ser assumida já no processo de projeto da infraestrutura escolar e na sociedade como um todo. A Educação Inclusiva tem que ser concebida como um espaço aberto à diversidade (ANTUNES, 2007).

A diversidade cultural, muitas vezes, está ausente do espaço escolar. Existe, ao contrário, uma cultura escolar que encaixa os objetos, os materiais didáticos, as músicas, as histórias e os pensamentos todos num mesmo padrão, numa mesma sequência, tempo e lugar. (REDIN, MÜLLER, REDIN 2007, p.17)

Segundo Kowaltowski (2013) as edificações escolares seguem um padrão, mas nem sempre os padrões levam em consideração algumas situações específicas, gerando espaços que ainda necessitam de muita adaptação, onde até uma simples relação de escala acaba atrapalhando a interação criança/ambiente. Pois é preciso esclarecer que as dinâmicas das relações existentes nas escolas são pouco conhecidas pelos arquitetos. Mas, se é desejado na arquitetura à interferência em uma situação real para adequação à finalidade a que se destina visando qualidade de vida do usuário, é necessário que esses conhecimentos sejam aprofundados. Nessa perspectiva, para desenvolver estudos de acessibilidade, é necessário ampliar o olhar e incluir novos elementos na avaliação do espaço que permitam examinar condições de apropriação para verdadeiro acolhimento.

Organizar o espaço em áreas e cantos temáticos é uma alternativa que possibilitará a interação das crianças com diferentes materiais, permitindoIhes um entendimento de uso coletivo do espaço, onde ao mesmo tempo são possíveis escolha individuais e grupais que certamente favorecem também a construção de sua autonomia. (REDIN, MÜLLER, REDIN, 2007, p. 104)

No caso dos espaços internos, um esforço nesse sentido vem sendo feito, desde 2008, por Magda Mostafa que, com intuito de formular diretrizes para o projeto, enumerou em suas pesquisas, sete requisitos fundamentais para ambientes internos voltados a essa demanda: acústicos, sequenciamento espacial, espaço de fuga, compartimentalização, transições, zoneamento sensorial e segurança.

No que diz respeito à audição, o ambiente acústico deve ser pensado de forma a minimizar o ruído de fundo, o eco e a reverberação. O que a autora chama de sequenciamento espacial diz respeito à organização lógica das áreas internas, baseada na programação horária de uso desses espaços.

Segundo Mostafa (2008), deve-se poder fluir, o mais perfeitamente possível, de uma atividade para a outra por meio de uma circulação unidirecional com o mínimo de interrupções. O objetivo do espaço de fuga, que pode ser um pequeno abrigo em uma área tranquila de um cômodo ou em todo um edifício, é proporcionar aos autistas um descanso da superestimulação encontrada nos seus ambientes de vivência. Ele deve ser um ambiente sensorialmente neutro, com estimulação mínima que pode ser personalizada pelo usuário para fornecer as condições ambientais necessárias a cada caso. 


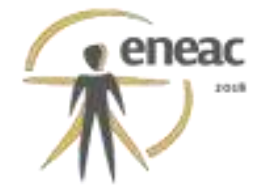

Figura 4: Cor pode ajudar na compartimentação do espaço

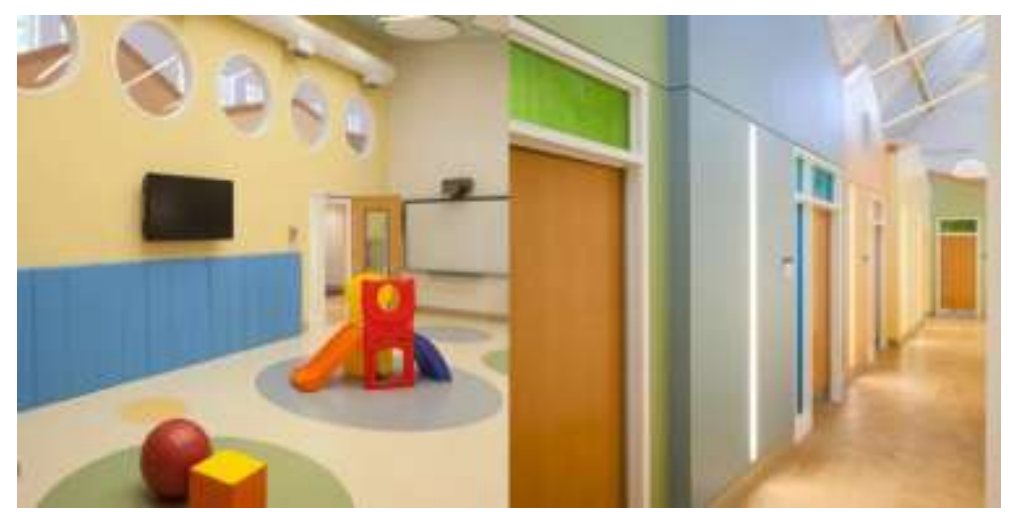

Fonte: Co. Design, 2016.

A compartimentalização se refere à necessidade de que cada ambiente possua uma função clara e uma apropriada qualidade sensorial, ou seja, a place for everything and everything in its place (Mostafa, 2008, p. 204). A zona de transição ajuda o usuário a recalibrar suas energias sensoriais no caso de mudar de um determinado nível de estímulo para outro. Por meio do zoneamento, pretende-se que os ambientes sejam projetados de acordo com as percepções sensoriais dos usuários ao invés de serem baseados em zonas funcionais ordinárias e generalizantes. Finalmente, a autora recomenda um cuidado especial com a segurança dos ambientes projetados para crianças autistas, as quais possuem um sentido alterado em relação ao seu entorno.

\section{O SOCIOCULTURAL: AMBIENTES CONSTRUÍDOS PARATODOS}

Relembrando o terceiro nível ambiental, que a AAMR classifica como importante para promover a interação entre indivíduos, o sociocultural é o mais distante da realidade de um autista, onde a cultura, leis e normas parecem não respeita-los totalmente, visto que o planejamento dos ambientes da cidade não pensa no real direito à acessibilidade para todos.

Com excesso de barulho de motos e carros passando nas ruas, calçadas descontínuas e praças sem playgrounds atrativos, as cidades não produzem ambientes acolhedores, onde uma simples arborização ajudaria a sombrear caminhos mais convidativos.

Assim como os arquitetos podem melhorar o ambiente escolar com pequenas adequações aqui sugeridas, os urbanistas também poderiam se conscientizar da crescente demanda da população portadora de TEA, que não pode ser excluída de uma vida sociocultural, limitando-se ao convívio no ambiente familiar, enclausurados em suas residências.

As cidades podem ser mais amigas e os planejadores devem pensar em ambientes construídos mais atraentes no espaço urbano como um todo. Nossas crianças não precisam de praças e de escolas só para elas; elas precisam da cidade que Ihes garanta espaços e tempos carregados de dignidade, respeito, ternura e aconchego. (REDIN, MÜLLER, REDIN, 2007, p. 07)

Se a falta de planejamento de cidades para o público infantil, já têm sido observada por importantes críticos do urbanismo moderno há décadas, pouco também foi feito para incluir crianças especiais que deveriam possuir o direito de acessar a todos os ambientes construídos da cidade. 


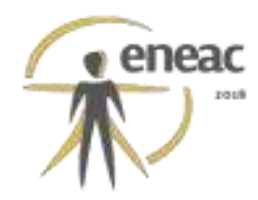

As crianças da cidade precisam de uma boa quantidade de locais onde possam brincar e aprender... precisam de um local perto de casa, ao ar livre, sem um fim específico, onde possam brincar, movimentar-se e adquirir noções do mundo. É essa espécie de recreação informal que as calçadas propiciam, e as calçadas movimentadas da cidade têm ótimas condições de fazê-lo. (JACOBS, 2007, p. 88)

Este artigo não pretende se aprofundar na esfera urbana, mas apenas deixar um alerta aos arquitetos que projetam escolas e diplomados também de urbanismo, que fiquem atentos ao elevado número de crianças autistas que merecem expandir os níveis de interação com a sociedade. $\mathrm{O}$ ambiente construído como o arranjo de características construtivas e físicas é indissociável do ambiente social é também considerado espaço de vida, leitura, sujeito à ocupação, modificação e/ou reinterpretação pelos usuários. O ambiente construído interage com o ambiente cultural, social e psicológico. É fruto do comportamento humano e resultado de uma série de normas e padrões sociais que influenciarão nas atividades ali realizadas (OKAMOTO, 2002).

O homem sempre moldou, planejou e construiu o espaço para as atividades de morar e sociabilizar, com o intuito de suprir suas necessidades vitais, conceituados como "construídos". Assim, "ambiente construído" pode ser definido como a criação do espaço vivencial, tanto para o indivíduo quanto para o meio social, onde se está em permanente deslocamento de uma atividade para outra (OKAMOTO, 2002, p. 149).

No ambiente construído, os elementos objetivos são: função, forma, cor, aeração, textura, temperatura ambiental, sonoridade, iluminação. Cada um desses valores resulta no espaço funcional, dimensionado e significante. Por meio deles, sentimos o ambiente e os fatos e eventos que nos chamam a atenção ou que selecionamos como de interesse, quando, então, temos a percepção da realidade de forma consciente. (OKAMOTO, 2002, p. 106).

No projeto de ambientes para crianças é preciso avaliar cuidadosamente vários aspectos espaciais. Ambientes bem projetados, segundo Trancik e Evans (1995), podem aumentar a competência dos usuários na apropriação ambiental, permitindo que façam uso das suas capacidades, ao mesmo tempo em que são estimulados a desenvolver habilidades mais complexas, além do nível de desenvolvimento em que estejam. Afinal, a criança têm necessidades de se apropriar do ambiente, ao contrário de serem intimidadas ou dominados. Elas precisam de liberdade para explorar e testar suas habilidades.

É possível projetar cidades mais habitáveis, como espaços e tempos para encontros e intercâmbios, com equipamentos e infraestruturas culturais, lúdicas e formadoras que contribuam para a melhoria da qualidade social da vida das pessoas. (REDIN, MÜLLER, REDIN, 2007, p 31)

Ao criar bons espaços públicos, os arquitetos e urbanistas devem considerar os efeitos que o projeto causa aos sentidos, colocando o corpo no centro de seus pensamentos:

Eu confronto a cidade com meu corpo; minhas pernas medem o comprimento da arcada e a largura da praça; meus olhos fixos projetam meu corpo na fachada da catedral, onde ele perambula sobre molduras e curvas, sentindo o tamanho de recuos e projeções; meu peso encontra a massa da porta da catedral e minha mão agarra a maçaneta enquanto mergulho na escuridão do interior. Eu me experimento na cidade; a cidade existe por meio de minha experiência corporal. A cidade e meu corpo se complementam e se definem. Eu moro na cidade, e a cidade mora em mim. (PALLASMAA, 2011, p. 37) 


\section{rane $^{\text {rane }}$}

Portanto os planejadores deveriam se atentar ao poder da arquitetura, que pode funcionar como uma casca protetora, amenizando as sensações corporais como as de calor ou excesso de ruído. Estas não são preocupações exclusivas aos cinco sentidos extremamente aguçados dos autistas, mas a todos os habitantes, que merecem espaços urbanos acessíveis e confortáveis, que convidem ao permanente convívio social em ambientes públicos mais agradáveis.

O esforço de oferecer melhores cidades para pedestres e ciclistas também significará, é claro, melhores condições para crianças, melhores oportunidades para idosos e um convite mais forte para que o exercício seja realizado em conexão com as atividades diárias na cidade. A oportunidade de praticar atividades criativas e culturais também será reforçada quando a "cidade cotidiana" for melhor para a atividade e permanência humanas. (GEHL, 2015, p. 161)

Assim acredita-se que investimentos em difundir melhor a importância da inclusão de crianças com TEA perante a sociedade irá trazer benefícios para a sociedade em geral, partindo do pressuposto que uma cidade acessível é uma cidade para todos.

\section{REFERÊNCIAS BIBLIOGRÁFICAS}

American Association on Mental Retardation. Mental retardation: definition, classification, and systems of supports. AAMR. Washington, 2002.

ANTUNES, Katiuscia Cristina Vargas. Uma leitura sociológica da construção do espaço escolar à luz do paradigma da educação inclusiva. Dissertação (Mestrado em Educação) - Faculdade de Educação, Universidade do Estado do Rio de Janeiro, Rio de Janeiro, 2007. Disponível em:

$<$ http://files.inclusaoescolar.webnode.com.br/200000005-663f466999/katiucia.pdf>. Acesso em 09 out. 2017.

ARCHDAILY. Creche D.S / HIBINOSEKKEI + Youji no Shiro. Disponível em: <https://www.archdaily.com.br/br/760933/creche-ds-hibinosekkei-plus-youji-no-shiro>. Acesso em 18 jan. 2018.

CHAVES DIAS, Ebiene et al. Dieta isenta de glúten e caseína no transtorno do espectro autista: uma revisão sistemática. Revista Cuidarte. Disponível em: <https://www.revistacuidarte.org/index.php/cuidarte/article/view/485/921>. Acesso em: 15 jan. 2018.

CO. DESIGN. How to design for Autism: The architect behind the Center of Autism and the Developing Brain says the key is to be sensitive to light, sight, textures, and sounds. Disponível em: $<$ https://www.fastcodesign.com/3054103/how-to-design-for-autism>. Acesso em 27 jan. 2018.

DÉOUX, Suzanne. Bâtir pour la santé des enfants. Andorra: Medieco Éditions, 2010.

DISCHINGER, Marta et al. Desenho universal nas escolas: Acessibilidade na rede municipal de ensino de Florianópolis. Florianópolis : PRELO, 2004.

HYPENESS. Pai capta universo particular do filho autista em projeto fotográfico sensível. Disponível em: <http://www.hypeness.com.br/2013/05/pai-capta-universo-particular-do-filho-autistaem-uma-serie-de-fotos-cheia-de-sensibilidade/>. Acesso em: 18 jan. 2018.

GEHL, Jan. Cidades para pessoas. São Paulo: Perspectiva, 2015. 


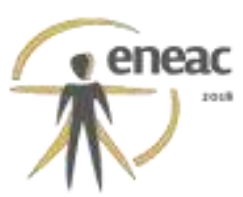

GRANDIN, Temple. 0 cérebro autista: Pensando através do espectro. Rio de Janeiro: Record, 2014.

JACOBS, Jane. Morte e vida de grandes cidades. São Paulo: Martins Fontes, 2011.

KOWALTOWSKI, Doris Catharine Cornelie Knatz. Arquitetura Escolar: o projeto do ambiente de ensino. São Paulo: Oficina de Textos, 2013.

MOSTAFA, Magda. An Architecture for Autism: Concepts of Design Intervention for the Autistic User. Archnet-IJAR, International Journal of Architectural Research. Vol. 2, 1, pp. 189-204, 2008.

OKAMOTO, Jun. Percepção Ambiental e comportamento: visão holística da percepção ambiental na arquitetura e na comunicação. São Paulo: Ed. Mackenzie, 2002.

PALLASMAA, Juhani. Os olhos da pele: a arquitetura e os sentidos. Porto Alegre: Bookman, 2011.

REDIN, Euclides. MÜLLER Fernanda. REDIN Marita Martins. Infâncias: cidades e escolas amigas das crianças. Porto Alegre: Mediação, 2007.

RIBEIRO, Lúcia Gomes. MONT'ALVÃO, Claúdia. MORAES, Anamaria. (org.). Ergonomia no Ambiente Construído. In: Ergodesign do Ambiente Construído e Habitado: Ambiente Urbano, Ambiente Público, Ambiente Laboral. Rio de Janeiro: IUsEr, 2004. p. 146.

SAVARIS. Lindas fotografias de crianças de férias sem seus gadgets! Disponível em: <http://www.savarisphotostudio.com.br/inspiracao-2/7361.html>. Acesso em 11 jan. 2018.

TRANCIK, Anika M.; EVANS, Gary W. Spaces Fit for Children: Competency in the Design of Daycare Center Environments. In: Children's Environments. Colorado, 1995. Disponível em: <http://www.colorado.edu/journals/cye>. Acesso em: 16 jan. 2018.

TUAN, Yi-Fu. Espaço e Lugar: A Perspectiva de Experiência. São Paulo: Difel, 1983. 